\title{
ANÁLISE DE DEGRADAÇÃO E RISCOS EM UM ELEMENTO DE PROTEÇ̃̃O DE CONCRETO ARMADO EM REGIÕES LITORÂNEAS: UM ESTUDO DE CASO NA CIDADE DE SÃO LUÍS - MA
}

\author{
MUNIZ, PEDRO \\ Engenheiro Civil \\ IPT - Instituto de Pesquisas Tecnológicas \\ São Paulo; Brasil \\ pedroguimaraesmuniz@gmail.com
}

\author{
PESTANA, FLÁVIO \\ Engenheiro Civil \\ Centro Universitário do Maranhão \\ Maranhão; Brasil \\ flavio.pestana@hotmail.com
}

\section{RESUMO}

Nos últimos anos, tem-se observado uma maior preocupação da comunidade de engenharia com a concepção, desempenho, longevidade e manutenção do patrimônio construído, principalmente por conta de alguns desses ativos causarem incidentes de repercussão nacional, acarretando em um custo holístico (social, econômico e sustentável) inimaginável. Cita-se o caso da "Ciclovia Tim Maia", no Rio de janeiro em 2016 e do "Viaduto da Marginal Pinheiros", São Paulo capital, 2019. O respectivo artigo faz uma abordagem objetiva e comparativa, apresentando o nível degradação e os riscos vitais embutidos em um elemento de concreto armado situado em região marinha. Este, composto em concreto armado sujeito a respingos de maré e sistematizado num local com elevado potencial turístico e de lazer, fatalmente acarretando numa grande quantidade de transeuntes. Para o desenvolvimento deste artigo, foram feitas inspeções visuais "in loco" em datas distintas com a finalidade de verificar seu estado de deterioração e uso corrente. Foram feitas referências à norma ABNT NBR 6118-2014- Estruturas de concreto armado - procedimento, no que ocasionou a constatação do seu descumprimento para taxa de cobrimento. Também foram utilizados alguns conceitos e recomendações para este tipo de problema, apresentadas pelo Professor Carlos Pinto Del Mar em sua apresentação ao primeiro Seminário Internacional de Manutenção do Patrimônio Público em São Paulo para obtenção de uma melhor engenharia pública. Por fim, apresenta-se dados do Tribunal de Contas da União - TCU, que convergem aos apontamentos do objeto estudado, tais como: inexistência de projetos e projetos deficientes ou desatualizados.

Palavras-chave: Concreto, Manutenção, Degradação.

\section{ABSTRACT}

In recent years, there has been a major concern of the community of engineering with the conception, performance, durability and maintenance of built heritage, mainly because of some of these assets cause incidents of national repercussion, resulting in a holistic cost (social, economic and sustainable) unimaginable. Cites the case of the "Tim Maia Bike", in Rio de Janeiro in 2016 and the viaduct of the Marginal Pinheiros, São Paulo, 2019. The respective article makes an objective and comparative approach, presenting the level degradation and the risks embedded in a vital element of reinforced concrete situated in marine region. This consists in reinforced concrete subject to splashing tide and systematized in a place with high potential for tourism and leisure, inevitably resulting in a large number of passersby. For the development of this article, visual inspections were made "in loco" on different dates in order to check its deterioration status and current use. References were made to the ABNT NBR 6118-2014 standard Reinforced concrete structures - procedure, which led to the verification of its non-compliance with the coverage rate. Some concepts and recommendations for this type of problem were also used, presented by Professor Carlos Pinto Del Mar in his presentation to the first International Seminar on Maintenance of Public Heritage in São Paulo to obtain better public engineering. Finally, data from the Federal Court of Accounts - TCU are presented, where they converge with the notes of the object studied, such as inexistence of deficient or outdated projects and projects.

Keywords: Concrete, Maintenance, Degradation. 


\section{INTRODUÇÃO}

É comum notar que durante algum tempo, achavam-se que as estruturas em concreto armado durariam para sempre e que apenas dando manutenções corretivas, as mesmas seriam capazes de retomar seu adequado desempenho. Sobretudo, é correto afirmar que esta cultura é uma inverdade e que o descumprimento de normativas técnicas básicas aliadas as boas práticas das estruturas em concreto, na maioria das vezes implicam em problemas de expressiva importância, o que podem acarretar em grandes acidentes. Com isso, para que se materialize toda e qualquer estrutura em concreto armado em padrões técnicos aceitáveis, deve-se obedecer ao uso da NBR 6118-2014, onde ficam estabelecidos parâmetros de dimensionamento e critérios de aceitabilidade para projetos das estruturas de concreto. Corroborando, pode-se ressaltar também a publicação da inovadora norma de desempenho em edificações habitacionais, a norma brasileira NBR 155752013 - Edificações habitacionais - Desempenho, que traz à tona conceitos de suma importância, tais como: Manutenibilidade e vida útil de projeto, tornando mais transparente as responsabilidades cabíveis a projetistas, executantes ou proprietários.

A degradação e o risco exemplificados neste estudo de caso estão inteiramente ligadas, mas nem sempre estão relacionadas, devido à grande quantidade de variáveis que são necessárias para se fazer uma análise. Essas variáveis partem desde a necessidade de apreciação do projeto original (inexistente) até uma metodologia executiva consolidada, que se adequa a uma boa seleção de materiais (sem registros). O que de fato sabe-se é que, no que tange a materialização deste elemento, existe a necessidade primordial de se fazer a retro análise do mesmo, redesenhando a estrutura e ao situa-la geograficamente, fazer uma checagem às normas cabíveis a estrutura estudada.

Ao fim do trabalho, explana-se o check-up e resultados da condição do elemento através de inspeções simples, auxiliada de "Vant" (veículo aéreo não tripulado) em dias e horários distintos sob a ótica autodestrutiva da estrutura mediante medições das taxas de cobrimento, deterioração e uso corrente. Explana-se também os conceitos de sustentabilidade na engenharia e visões que podem ser possíveis alternativas de solução para este tipo de problema muito usual no dia-dia dos brasileiros, conforme aponta o Tribunal de Contas da União - TCU (2017) em seus dados das auditorias feitas em obras públicas

Ao fim, são indicadas opiniões feitas por membros da classe de engenharia europeia no último XI CBPE - Congresso Brasileiro de Pontes e Estruturas (2019), na qual baliza conceitos para uma nova mentalidade da engenharia brasileira, cabível ao elemento de estudo, servindo como base para que se possa evitar a repetição desta cultura nas gerações futuras.

\section{DESENVOLVIMENTO DO TEMA}

Em linhas gerais, os primeiros guarda-corpos (elementos de proteção) surgiram em embarcações marítimas com o intuito de evitar que o balanço do mar fosse capaz de arremessar marinheiros mar à fora. Com o passar dos tempos, passou-se a utilizar este elemento, antes moldado na própria madeira das antigas embarcações, hoje sobretudo como elemento arquitetônico, estando presente na maioria das habitações, espaços públicos e pontes. A partir daí, evoluiu-se a concepção para as mais diversas tipologias, materiais e formas, no que resultou o surgimento da norma brasileira ABNT NBR 14718 - Esquadrias - Guarda Corpos para edificação, com o objetivo de definir os critérios e condições para seu uso, garantindo assim maiores condições de segurança na sua disposição geométrica funcional. O guarda-corpo constituído em concreto armado, possui como produto final a obtenção de elevada resistência, resistência essa, capaz de fazer jus a sua função de garantir que um corpo ou mais ao exercer uma ação em um sentido, sofra uma a reação de sentido oposto, que é suficientemente capaz de resistir as cargas solicitadas sem colapsar. Ressaltando que essa é a propriedade mais valorizada do concreto armado, sua capacidade material em receber uma tensão sem haver seu rompimento segundo, como afirma MEHTA e MONTEIRO (2008, p.49).

Para que a estrutura possa desenvolver seu esperado desempenho e principalmente sua durabilidade, torna-se primordial uma boa concepção e execução, correspondendo estritamente ao detalhamento do projetista responsável. Assim, daremos ênfase as premissas trazidas pela NBR 6118-2014, onde se explana conceitos fundamentais que parametrizam várias premissas de projeto. 
Para tanto, traz-se destaque para o que se diz tal norma quanto a classe de agressividade mediante a localização da estrutura para efeito de cobrimento nominal, conforme imagem a seguir:

Tabela I - NBR 6118-2014

\begin{tabular}{|cccccc|}
\hline Tipo de & Componentes ou & \multicolumn{4}{c|}{ Classe de Agressividade } \\
estrutura & Elementos & I & II & III & IV \\
& & \multicolumn{4}{c}{ Cobrimento Nominal } \\
Concreto & Lajes & 20 & 25 & 35 & 45 \\
armado & Vigas/Pilar & 25 & 30 & 40 & 50 \\
& Elementos em contato & 30 & & 40 & 50 \\
& com o solo & & & & \\
& &
\end{tabular}

Fonte: Adaptado pelo Autor

A adaptação feita da norma NBR 6118-2014, vista acima, deixa claro o que é estabelecido qual deve ser o cobrimento mínimo relacionado para cada respectivo elemento em concreto armado de acordo com sua classe de agressividade Ambiental.

Para complementar estes parâmetros de maneira bem simplória, a norma preconiza alguns outros critérios simples, porém muito relevantes, tais como o de relação água sobre o cimento e taxa mínima de cimento na mistura do concreto à ser executado para a estrutura. Vale também ressaltar, o risco de deterioração da estrutura, também disposta na norma NBR 6118-2014, conforme a imagem abaixo:

Tabela II - NBR 6118-2014

\begin{tabular}{|cccc|}
\hline $\begin{array}{c}\text { Classe de } \\
\text { agressividade } \\
\text { ambiental }\end{array}$ & Agressividade & $\begin{array}{c}\text { Classificação geral do } \\
\text { tipo de ambiente para } \\
\text { efeito de projeto }\end{array}$ & $\begin{array}{c}\text { Risco de } \\
\text { deterioração da } \\
\text { estrutura }\end{array}$ \\
\hline I & Fraca & Rural/submersa & Insignificante \\
\hline II & Moderada & Urbana & Pequeno \\
\hline III & Forte & Marinha/industrial & Grande \\
\hline IV & Muito forte & $\begin{array}{c}\text { Industrial/respingos de } \\
\text { maré }\end{array}$ & Elevado \\
\hline
\end{tabular}

Fonte: Adaptado pelo Autor

Das informações dispostas, entende-se que a definição do ambiente de situação da estrutura, aliado ao conhecimento dos critérios apresentados tabelas I e II são de primordial contribuição para a elaboração de um elemento durável em concreto armado nas condições as quais o mesmo fora concebido. Sendo assim, estes são parâmetro que tendem a garantir um melhor desempenho da estrutura, refletindo diretamente na sua durabilidade, evitando problemas precocemente e também a necessidade recorrente de correções não programadas.

\subsection{Sustentabilidade aplicada}

O concreto armado é composto do concreto e do aço. Estes insumos são resultantes do processamento industrial de sua matéria prima natural, matérias essas que estão disponibilizadas finitamente na natureza. Dentro do conceito "triple botton line" podemos ter sua relação intimamente ligada ao desenvolvimento sustentável das construções, representando assim, preocupações relativas ao aspecto social, político e econômico.

Tal conceito é fortemente trabalho na França e anda em passos lentos no Brasil, onde leva em consideração todo o ciclo de vida do produto, materiais utilizados desde seu projeto, construção, operação e manutenção, em direção do esgotamento da sua função. 
É dentro deste modelo de projeto e construção que a engenharia brasileira tenta galgar em um ambiente urbano mais sustentável, conforme demostrado a seguir:

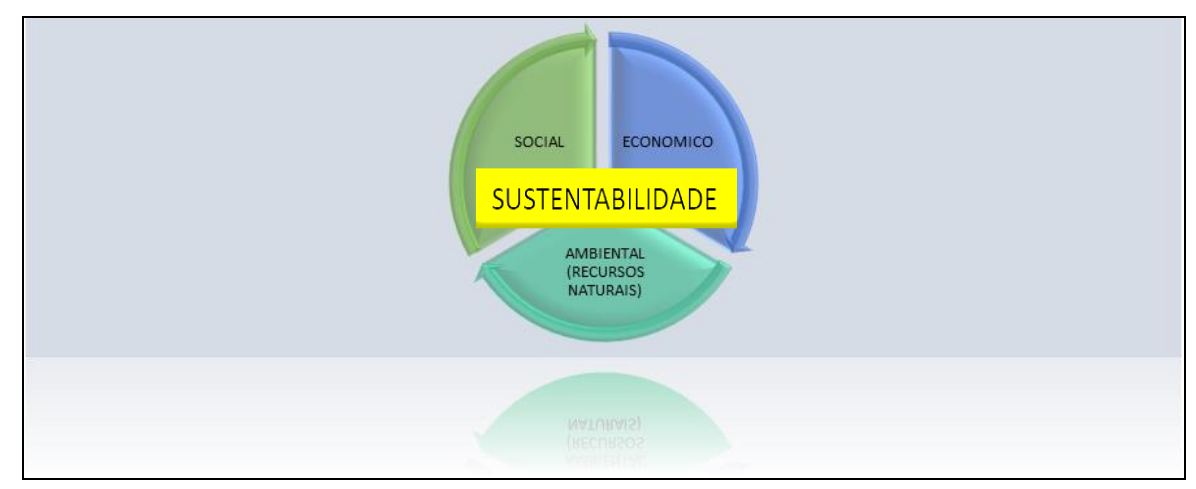

Figura 1 - Conceito "Tripple Botton Line"

Em linhas gerais, os três fatores devem ser amplamente debatidos durante a fase de concepção e acompanhados durante a execução de uma estrutura, de maneira que a três áreas possam se equilibrar entre práticas viáveis, suportáveis e justas (MELHADO, A, 2013).

Ao se tratar da compra de uma obra de engenharia pública, por força de lei, deve ser feita através da lei de licitações, estabelecendo como vencedor a proposta mais vantajosa, atendendo a diversos princípios públicos, sendo o mais relevante para este tipo de compra, a economicidade, ou seja, o menor preço. Segundo o Professor Carlos Pinto del Mar, na sua apresentação ao seminário Internacional de Manutenção do Patrimônio Público, Mar (2019), a aquisição da engenharia mais barata, de fato, não é a que custa o menor preço. Logo, ao não se conceber uma estrutura de concreto armado que atenda as preconizações da norma NBR 6118-2014 citadas na imagem 1 e 2, faz-se da engenharia mais barata, uma engenharia que não se adequa os conceitos sustentáveis supracitados. Tornando esta engenharia disfarçada de custo baixo em sua implantação, mas durante os anos vem acompanhada de um custo oneroso embutido, acarretando em diversas manutenções corretivas, riscos estruturais e transtornos as pessoas.

Após a publicação em 2013 da lei de desempenho de edifícios habitacionais a NBR 15575-2013 que leva em consideração todo ciclo de vida do produto, ficou ainda mais evidente, que deve ser avaliada uma obra de engenharia por um olhar díspar, enxergando-se todo seu conjunto e não somente o custo inicial que é o usualmente especificado nos termos de licitações, conforme demonstrado na imagem em seguida:

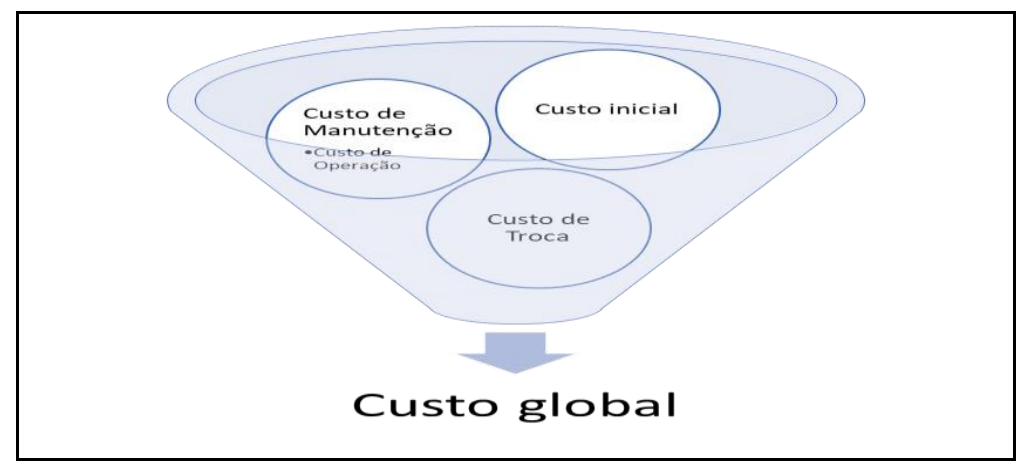

Figura 2 - Custo Global de uma Edificação

Nota-se que para se tornar a proposta mais vantajosa na compra de uma obra de engenharia, não se deve avaliar apenas o custo inicial, mas sim, todo seu ciclo de vida, somado ao custo inicial, custo de operação, custo de manutenção e até mesmo o custo de uma possível troca (reposição). Assim, é de se perceber mais claramente as vantagens de obter de um projeto bem elaborado e durável, consequentemente acarretando na diminuição do consumo dos recursos finitos promovendo um maior desenvolvimento sustentável para a engenharia à benefício da população. 


\section{RESULTADOS E DISCUSSÕES}

A estrutura estudada faz parte de um elemento dentro pacote de obras da Avenida Litorânea que foi inaugurada em São Luís do Maranhão no ano de 1990, SILVA et. al. (2014). Foram feitas consultas aos órgãos públicos responsáveis que não se manifestaram a respeito da existência de projeto original.

Devido a inexistência do projeto original da obra, fez-se o trabalho de reengenharia do módulo padrão da estrutura. Com características usuais de 2 pilaretes de concreto armado com $1 \mathrm{~m}$ de altura e secção típica de $20 \mathrm{~cm}$ x $20 \mathrm{~cm}$, que estão associados à duas vigas do mesmo material, sendo uma superior e outra intermediaria com base de $6 \mathrm{~cm}$ e altura de $25 \mathrm{~cm}$, conforme a figura 3 .

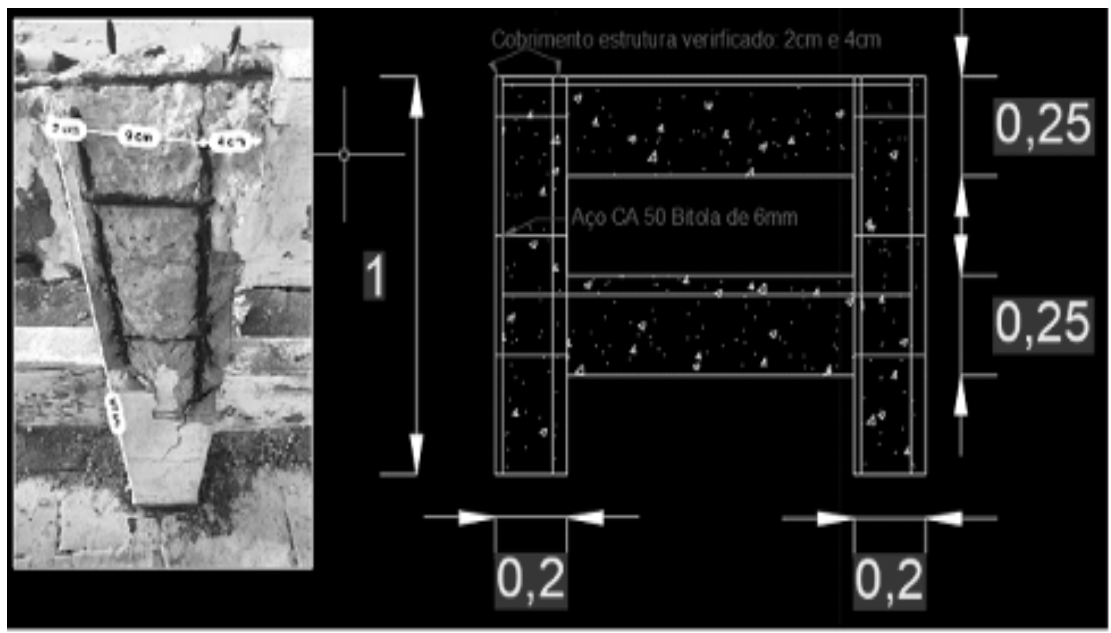

Figura 3 - Assbilt da estrutura estudada.

A estrutura está localizada numa região litorânea com amplitude máxima de maré que pode chegar até 7 metros, acometida a respingos semi-diurnos. Também vale ressaltar que a mesma está situada em uma praça de alimentação na praia de São Marcos e que durante os 12 meses do ano possui uma umidade relativa do ar aproximada de $70 \%$ e temperaturas médias de 30 graus para máxima e 22 graus para mínima segundo dados do Roteiro Norte (2011).

Ainda se tratando da estrutura, só que como um todo, a mesma possui uma extensão de aproximadamente 200 metros lineares, servindo de proteção para adultos e crianças quanto a queda livre para um nível inferior de até 5 metros de altura, deixando em risco evidente a vida dos usuários na região, conforme a figura 4.

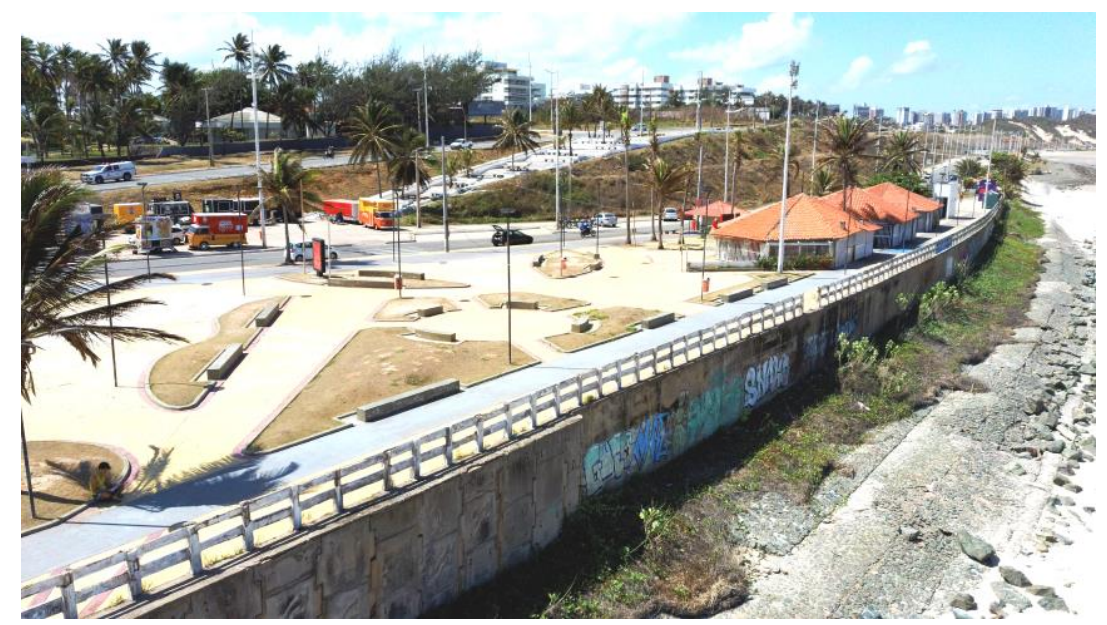

Figura 4 - Foto Panorâmica da Extensão da estrutura Retirada por "VANT". 
A estrutura de proteção em concreto armado com pintura de baixa superfície na cor branca é um elemento fundamental para este espaço público que é ponto de referência para turistas e frequentadores na busca de espaços públicos que ofereçam a oportunidade de lazer e alimentação na cidade de São Luís do Maranhão.

As inspeções simples foram feitas em datas distintas, possibilitando a medição de taxas de cobrimento e registros correntes, com o auxílio de uma câmera fotográfica, trena, paquímetro e "Vant". Na primeira inspeção, foi possível verificar a ausência de uma parte deste elemento, geometria e sua disposição quanto ao ambiente público conforme a figura 5 .

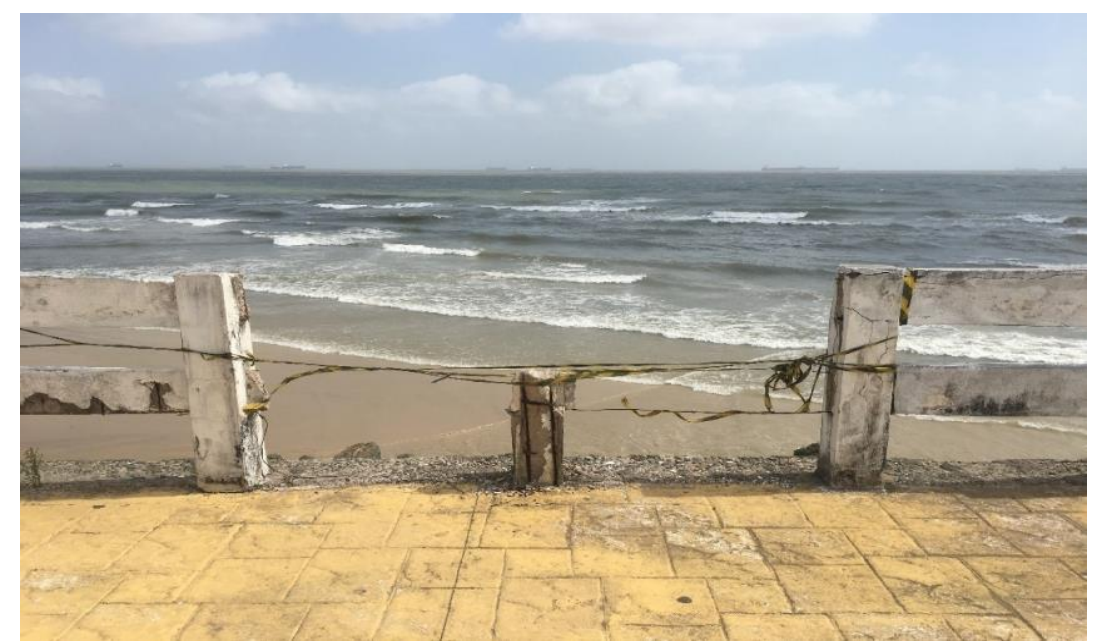

Figura 5 - Ausência de um módulo da estrutura, autodestruído.

Percebe-se a ausência quase que total do elemento em condição de maré alta, restando apenas $20 \mathrm{~cm}$ do pilar de sustentação em concreto armado que está em contato direto com a superfície.

Na mesma inspeção foi possível detectar algumas manifestações patológicas, dentre elas, as de maior destaque foram as manchas, fissuração, desplacamento do concreto, armadura seccionada e ausência de armadura, conforme demonstrado figura 6.

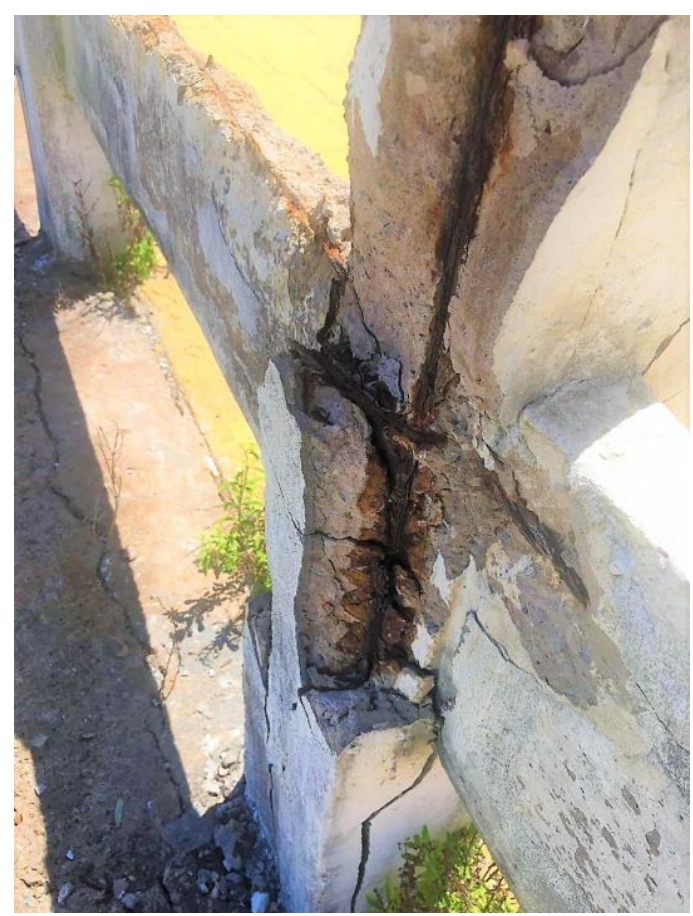

Figura 6 - Corrosão e secionamento da armadura. 
Com a inspeção realizada, pode-se constatar a necessidade de correção em diversos trechos, ainda que os elementos se apresentassem materializados, os mesmos já apresentavam aberturas no concreto, facilitando assim o ataque da sua armadura interna, vale ressaltar também como necessidade, a reconstrução total de alguns elementos originais.

Através das medições feitas "in loco" verificou-se nos principais pontos (mais deteriorados) que as maiores taxas de cobrimento dos elementos foram iguais ou inferiores a $3 \mathrm{~cm}$. Embora mesmo estando o elemento disposto numa zona de classificação IV e com uma probabilidade risco de deterioração elevada da estrutura. A seguir, a tabela III, apresenta uma visão sobre as 5 das medições feitas e suas taxas de cobrimento.

Tabela III - Inspeções 1 a 5

\begin{tabular}{|ccc|}
\hline Número & Cobrimento "in situ" & Atendimento à NBR 6118-2014 \\
\hline 1 & $3 \mathrm{~cm}$ & Não \\
\hline 2 & $2,5 \mathrm{~cm}$ & Não \\
\hline 3 & $2 \mathrm{~cm}$ & Não \\
\hline 4 & $2 \mathrm{~cm}$ & Não \\
\hline 5 & $2,5 \mathrm{~cm}$ & Não \\
\hline \multicolumn{3}{|c|}{ Fonte: Adaptado pelo Autor } \\
\hline
\end{tabular}

Em 5 medições feitas em locais distintos dentro da continuidade da estrutura com cerca de 200 metros, não houve nenhuma taxa de cobrimento que atendesse satisfatoriamente à norma NBR 6118-2014. É relevante ainda dizer que, na estrutura inspecionada há cobrimento evidenciado em valores de $2 \mathrm{~cm}$, satisfazendo apenas ambientes rurais, o que torna esta estrutura não só incompatível com o ambiente marinho, mas incompatibilizando-a para qualquer região urbana da capital maranhense.

\section{CONSIDERAÇÕES FINAIS}

Mediante a realização de inspeções simples da estrutura e comparativos documentais da engenharia pública, ou seja, a engenharia que é de responsabilidade do estado, pudemos observar que não houve a utilização de um projeto que obedecesse minimamente às preconizações estabelecidas pela NBR 6118-2014.

Afirma-se ainda que todos os elementos que constituem essa estrutura possuem implicações estruturais significativas e nível de deterioração que indique um comprometimento quanto à sua estabilidade vide o exemplo do módulo da estrutura que já se encontra ausente. Observa-se que seu poder de resposta quanto sua normal utilização já não atende sua concepção inicial, sendo necessário um novo estudo de engenharia.

Durante o dia, pode-se constatar a normal utilização da estrutura em situação de deterioração e de projeto constatado incompatível, pondo em risco a vida das pessoas que não possuem discernimento suficiente para identificar os riscos ocultos nesta estrutura.

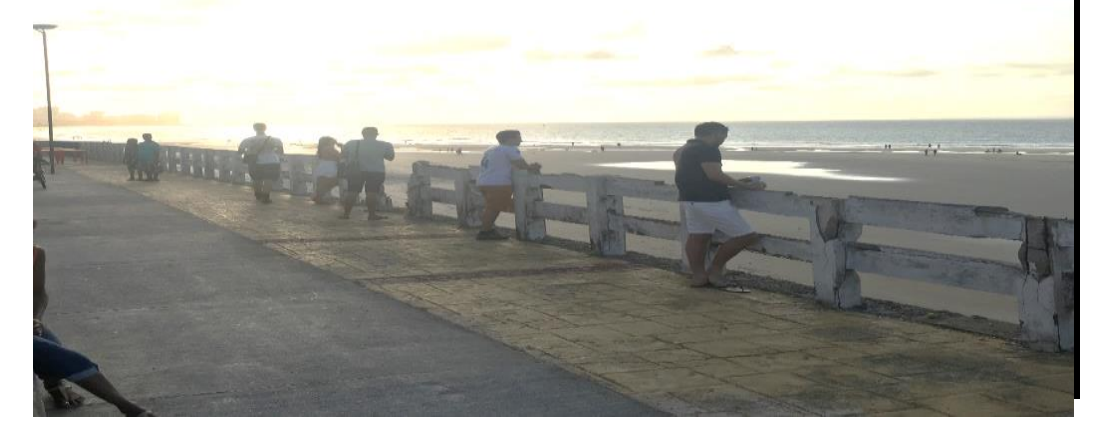

Figura 7 - Frequentadores utilizando o elemento de proteção deteriorado. 
Seguramente, pode-se perceber que pessoas utilizam a estrutura comprometida, trazendo riscos a sua vida caso a estrutura venha a não suportar os esforços exercidos pelos seus utilizadores, agravado pela falta de sinalização de condição insegura.

Com alguns dados obtidos através do membro do TCU, o Professor André Pachioni Baeta, podemos reafirmar com maior convicção nas duas figuras em seguida uma necessidade de mudança de paradigma para os gestores de obras públicas de engenharia no brasil.

Tabela IV - Principais irregularidades Constatadas pelo TCU.

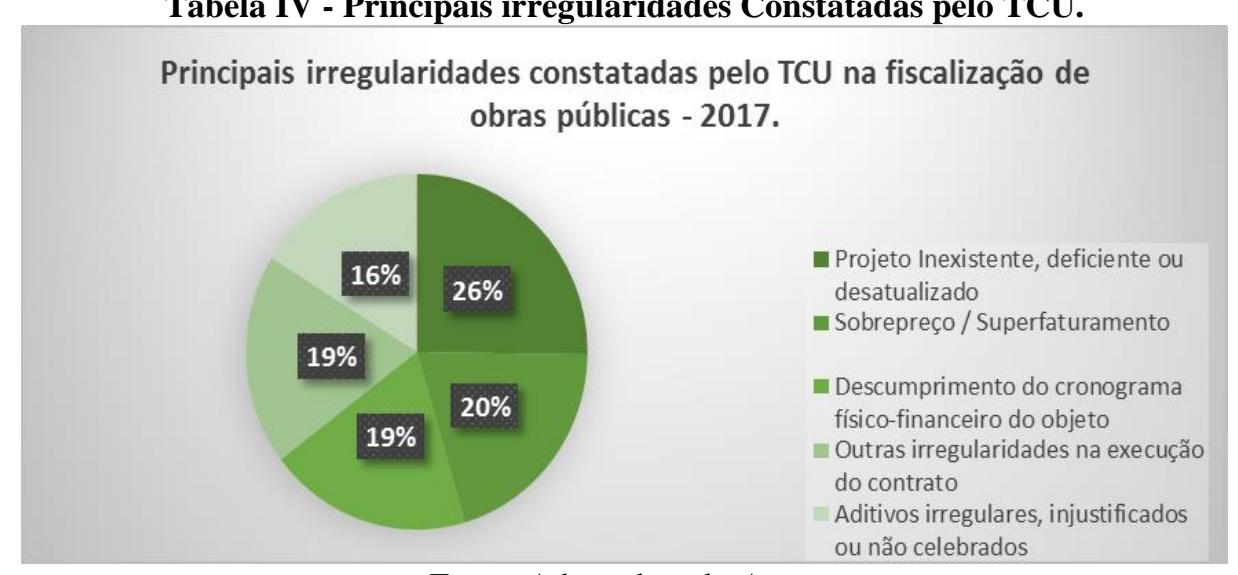

Fonte: Adaptado pelo Autor

Com a interpretação gráfica do TCU, pode-se notar que se trata de projeto inexistente, deficiente ou desatualizado uma das maiores ocorrências dentro da prestação de serviço de engenharia pública. Sobretudo, ainda que essa realidade, constatada e evidenciada, não fosse uma verdade, temos que analisar a imagem seguinte:

\section{Tabela V - Fiscalizações com execução acima de $75 \%$}

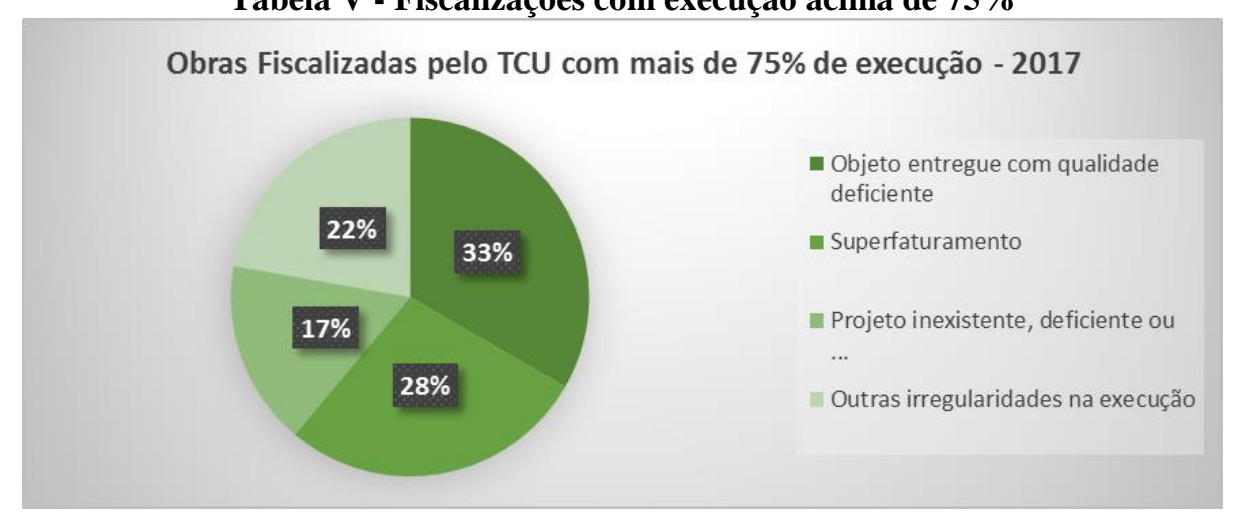

Fonte: Adaptado pelo Autor

A execução obras de engenharia sem projeto, com projeto deficiente ou desatualizado, ainda existe o fator de qualidade, que corresponde a $33 \%$, ou seja, a cada 10 obras, 3 possuem projeto ineficiente ou nem possuem projetos, no que cabe ao emprego de materiais com qualidade inferior ou técnicas construtivas incompatíveis.

Toda essa realidade agrava negativamente o conceito "triple botton line" para estrutura estudada, pois:

$\checkmark$ Economicamente a depreciação acelerada do bem construído acarreta em novos gastos com manutenção corretiva ou possível reposição gerando custos não previstos.

$\checkmark$ Socialmente a necessária interdição do equipamento/espaço público diminui a qualidade de vida das pessoas pondo riscos à integridade física durante seu uso indevido. Existe também o custo monetário social, por se tratar de uma estrutura com necessidade de atuação não programada, ou seja, gastos imprevistos, este provisionamento de recursos fatalmente irá comprometer outros departamentos da esfera pública, tais como: saúde, segurança e educação.

$\checkmark$ Ambientalmente a cada intervenção, seja corretiva ou reposição, acarreta-se numa nova utilização de recursos naturais, nas matérias primas esgotáveis (água, areia, brita, cimento, ferro, fôrmas de madeira). 
Além disso, vale ressaltar a possibilidade da implantação de melhorias mediante alguns novos conceitos para os futuros projetos de novos equipamentos, sejam públicos ou privados. Conceitos estes que vêm sendo debatidos e trabalhados no cenário internacional, que também foram colocados em evidência no último Congresso Brasileiro de Pontes e Estruturas (2019).

Opiniões que quebram o paradigma quanto as diretrizes do dimensionamento aplicáveis a estes tipos de estrutura, sendo:

$\checkmark \quad$ A robustez, que é a capacidade de uma estrutura, sujeita a carga acidental ou excepcional, de sustentar danos locais em alguns componentes estruturais sem experimentar um grau desproporcional de sofrimento ou colapso geral, Fib Model Code for Concrete Structures (2010).

$\checkmark$ A redundância, que é a capacidade do sistema de redistribuir entre seus membros a carga que não pode mais ser sustentada por outros membros danificados, BIODINI et al. (2008)

$\checkmark \quad$ A resiliência, que está relacionada à capacidade de um sistema suportar eventos incomuns e à rapidez com que o sistema pode se recuperar desses eventos, Corres (2019).

Com a união destes novos conceitos supracitados e suas aplicações as estruturas de concreto armado, sejam elas de iniciativas públicas ou privadas, tratar-se-á de haver uma quebra de paradigma no que tange a estes problemas visualmente usuais, porém pouco evidenciados dentro das infraestruturas concebidas em concreto e aço. 


\section{REFERÊNCIAS}

ASSOCIAÇÃO BRASILEIRA DE NORMAS TÉCNICAS. NBR 6118:2014. Projeto de estruturas de concreto Procedimento. Rio de janeiro, RJ, 2014.

ASSOCIAÇÃO BRASILEIRA DE NORMAS TÉCNICAS. NBR 15575:2013. Edificações habitacionais Desempenho. Rio de janeiro, RJ, 2013.

ASSOCIAÇÃO BRASILEIRA DE NORMAS TÉCNICAS. NBR 14718:2019. Esquadrias - guarda-corpos para edificação - Requisitos, procedimento e métodos de ensaio. Rio de janeiro, RJ, 2014.

BIONDINI, F.; FRANGOPOL, D. M.; RESTELLI, S. On Structural Robustness, Redundancy, and Static Indeterminacy. In: Structures Congrss 2008: Crossing Borders, ASCE, april 24-26, Vancouver, British Columbia, Canada.

BIONDINI, F.; FRANGOPOL, D. M.; MALERBA, P. G. Uncertainty effects on lifetime structural performance of cable-stayed bridges. Probabilistic Engineering Mechanics, 23, p. 509-522, 2008.

BIONDINI, F., FRANGOPOL, D. M. Long-term performance of structural systems. Structure and Infrastructure Engineering 2008;4(2):72. Special Issue, Fabio Biondini (ed.), Taylor \& Francis.

BRASIL. Tribunal de Contas da União; BAETA, A. P. Auditoria de Obras Públicas - Módulo 1: Orçamento de Obras. 2. ed., 28 p., Instituto Serzedello Corrêa, Brasília, DF, 2012.

BRASIL. Tribunal de Contas da União; BAETA, A. P. Auditoria de Obras Públicas - Módulo 2: Auditoria de Obras Públicas. 19 p., Instituto Serzedello Corrêa,, Brasília, DF, 2011.

BRASIL. Tribunal de Contas da União; BAETA, A. P. Auditoria de Obras Públicas - Módulo 3: Práticas de Auditoria e Análise da Contratação. 31p., Instituto Serzedello Corrêa, Brasília, DF, 2012.

CORRES, Hugo. Morandi, the Polcevera Viaduct in Genoa: Past Opportunities and Present and Future Needs of Maintenance and Repair of Built Heritage. In: CONGRESSO BRASILEIRO DE PONTES E ESTRUTUTAS, 21. 2019, São Paulo. Memorias. São Paulo: Abece \& Abpe, 2019. p. 1 - 143.

MAR, Carlos Pintor del. ABNT NBR 15575: Norma de Desempenho. In: SEMINÁRIO INTERNACIONAL DE MANUTENÇÃO DO PATRIMÔNIO PÚBLICO, 1, 2019, São Paulo. Proceedings... . São Paulo: Instituto de Engenharia, 2019. v. 1.

MARINHA DO BRASIL. Centro de Hidrografia da Marinha - Roteiro Costa Norte. Disponível em:< https://www.marinha.mil.br/chm/dados-do-segnav-publicacoes/roteiros>. Acesso em: 18 de jun. de 2011.

MEHTA, P. K.; MONTEIRO, P. J. M. Concreto: estrutura, propriedades e materiais. 3. ed. São Paulo: Pini, 2008.

MELHADO, A. R.; SANTOS, A.; MELHADO, S.; GURGEL, A. Projetar e Construir Bairros Sustentáveis. Editora: Pini. 260f. São Paulo, SP, 2013.

SILVA, A. L.; MONTEIRO, T. O.; SANTOS, M. S.; DUARTE, D. S.; SANTOS, K. M. S.; MENEZES, S. L. Estudo teórico do processo corrosivo da ponte sobre o Rio Calhau na Avenida Litorânea em São Luís-MA. In: $54^{\circ}$ Congresso Brasileiro de Química. Anais eletrônico do 54º congresso brasileiro de química. Natal, RN, 2014.

WALRABEN, J.; VLIET BIGAJ-VAN, A. Fib Model Code for Concrete Structures. Lausanne, Suiça, 2010. 